\title{
TRANSPARENCIA PARLAMENTARIA EN EL DISTRITO FEDERAL
}

\section{Corazón Raquel LOZANO GONZÁLEZ*}

\begin{abstract}
RESUMEN. La transparencia parlamentaria en la Asamblea Legislativa del Distrito Federal tiene como elementos relevantes de su práctica, en la última década, la creación de dos órganos: la Oficina de Información Pública y la Comisión de Transparencia a la Gestión. La primera como un espacio donde se materializa el ejercicio del acceso a la información y la transparencia del trabajo legislativo, y la segunda como espacio de discusión, análisis y dictamen en asuntos relativos a la legislación local. El presente ensayo se enfoca en identificar los principales avances y retos a partir de la existencia de estos órganos, considerando que prevalece cierta opacidad en el proceso legislativo que se lleva a cabo en las comisiones legislativas. Se toma como referente de análisis a la Comisión de Transparencia a la Gestión y a la Oficina de Información Pública, como unidad administrativa que procesa y atiende solicitudes de información.
\end{abstract}

PALABRAS CLAVE: transparencia parlamentaria, acceso a la información, comisiones legislativas, proceso legislativo y parlamento abierto.

*Doctorante en ciencias políticas y sociales por la UNAM, raquelozanog@gmail.com. Fecha de recepción: 8 de septiembre de 2015.

Fecha de dictamen: 29 de septiembre de 2015. 


\section{ABREVIATURAS Y SIGLAS}

CPEUM Constitución Política de los Estados Unidos Mexicanos, Diario Oficial de la Federación del 10 de julio de 2015.

EGDF Estatuto de Gobierno del Distrito Federal, Diario Oficial de la Federación del 27 de junio de 2014.

48 LFA Ley Federal de Archivos, Diario Oficial de la Federación del 23 de enero de 2012.

LADF Ley de Archivos del Distrito Federal, Gaceta Oficial del Distrito Federal del 28 de enero de 2015.

$\because$ LOALDF

Ley Orgánica de la Asamblea Legislativa del Distrito Federal, Gaceta Oficial del Distrito Federal del 24 de junio de 2015.

LTAIP

Ley de Transparencia y Acceso a la Información del Distrito Federal, Gaceta Oficial del Distrito Federal del 18 de diciembre de 2014.

\section{INTRODUCCIÓN}

La transparencia parlamentaria constituye una condición que dota de legitimidad al órgano legislativo como representante de los intereses generales de los ciudadanos, contrapeso de los poderes Ejecutivo y Judicial, así como en lo que respecta a informar a sus representados sobre sus decisiones y justificarse ante ellos.

Entre las funciones de un parlamento se encuentra la de ser un órgano generador de leyes, y en la esfera social se espera que desarrolle su función legislativa en un marco de transparencia y rendición de cuentas. A su vez, en los parlamentos se hace efectiva la representación política, el control del Poder Ejecutivo, así como los procesos de toma de decisiones políticas que inciden socialmente.

En materia de transparencia llega a presentarse cierta incompatibilidad entre lo establecido en las normas y los aspectos de la práctica cotidiana en los congresos locales. Esta situación ha sido objeto de discusiones y diversos posicionamientos en relación con las características de la información que se publica, la cual puede adolecer de claridad, ser incompleta, o bien, estar disponible en formatos demasiados complejos y no estar actualizada. La opacidad suele persistir en materias como ejercicio del gasto de legisladores, trabajo en comisiones y personal de los congresos (Alcántara y García, 2013: 5, Índice de Transparencia Legislativa, 2014). 
México cuenta con un grado de avance general del 37\% en materia de transparencia, esto según el reporte de resultados de la Red Latinoamericana por la Transparencia Legislativa. En dicho documento se analizan distintas categorías y se establecen grados de avance por cada una, a saber: labor del congreso o asamblea con el $46 \%$, normatividad con el $47 \%$, en presupuesto y gestión administrativa con $21 \%$, y en mecanismos de participación, atención ciudadana y rendición de cuentas con el 33\%.

En lo referente a los congresos locales mexicanos, la Alianza por un parlamento abierto dio a conocer en 2014 los resultados de su diagnóstico para los treinta y dos congresos de México en cuanto al grado de avance de los diez principios de un Parlamento Abierto. Al respecto, la Asamblea Legislativa del Distrito Federal presentó un grado de avance "insatisfactorio" en las categorías de transparencia en información sobre legisladores y servidores públicos (50\%); accesibilidad y difusión (33\%); de "muy insatisfactorio" en información presupuestal y administrativa (33\%), y en legislar a favor del gobierno abierto. Se reporta como "no cumple" en datos abiertos y no propietario, y en conflictos de interés.

En tal sentido, el presente ensayo está centrado en el estudio del Poder Legislativo, concretamente en relación con la transparencia parlamentaria en el órgano denominado Asamblea Legislativa del Distrito Federal, considerando que presenta ciertos avances en las últimas dos legislaturas en el impulso a la transparencia legislativa y la rendición de cuentas. Lo anterior a partir de la creación de la Oficina de Información Pública en 2004 y de la Comisión de Transparencia a la Gestión en 2009. La pregunta que se intenta responder en el presente ensayo es ¿cuáles son los avances en materia de transparencia parlamentaria en la Asamblea Legislativa del Distrito Federal y qué retos se identifican para lograr las condiciones favorables hacia un parlamento abierto?

La discusión está enfocada en comprender de qué manera la existencia de una Comisión de Transparencia a la Gestión puede representar un avance importante para legislar a favor de un parlamento abierto así como de la Oficina de Información Pública que representa la unidad administrativa que está en contacto con la ciudadanía, en tanto que es la que transmite las peticiones de información a las áreas correspondientes del órgano legislativo. La institucionalidad y calidad de los procesos de la Oficina es condición importante para atender de forma diligente las solicitudes recibidas para garantizar un acceso oportuno a la información, así como en términos de transparencia en la información pública de oficio. Se aborda su estudio en este ensayo bajo la premisa de que constituyen espacios idóneos para impulsar avances legislativos a favor de gobierno abierto, así 
como una conducta honesta, ética y en el marco de la legalidad, por parte de los servidores públicos de la propia Asamblea.

El tema es relevante en razón de que sólo existe un primer estudio sobre unidades de acceso a la información de Ríos y Dirk (2012), pero en relación con el trabajo legislativo de comisiones de transparencia en congresos locales de México no se ubicó algún estudio.

Para responder a la pregunta de trabajo en un primer apartado se presentan consideraciones generales sobre transparencia parlamentaria, parlamento abierto y rendición de cuentas. En segundo lugar, se hace referencia a la organización y funcionamiento de la Comisión de Transparencia a

- la Gestión creada en 2009, así como a la Oficina de Información Pública

- que fue creada por acuerdo de la Comisión de Gobierno en la III Legislatura en 2004. La Comisión es un espacio legislativo de discusión, análisis y dictamen en asuntos relativos a la legislación local en materia de transparencia, rendición de cuentas y gobierno abierto. Por su parte, la Oficina es la encargada de brindar información pública a la ciudadanía respecto del trabajo legislativo que realizan los diputados en comisiones, su productividad legislativa, presupuestos, así como las principales decisiones políticas que determinan la orientación de los recursos públicos que son destinados para atender necesidades sociales.

El documento se basa en una revisión documental de leyes, informes, actas, versiones estenográficas, acuerdos, listas de asistencia, y documentos diversos del portal de transparencia, así como los resultados del diagnóstico de la Alianza por el Parlamento Abierto en 2014. A partir de ello se recabó información con la finalidad de conocer en qué medida la Comisión de Transparencia a la Gestión y la Oficina de Información Pública han contribuido a lograr condiciones favorables para legislar a favor de un parlamento abierto.

\section{TRANSPARENCIA, RENDición DE CUENTAS, GOBIERNO Y PARLAMENTO ABIERTO}

La transparencia constituye una condición necesaria para lograr la rendición de cuentas, en virtud de que el Poder Legislativo tiene la función de "controlar la acción del poder y a nombre de la sociedad exigir cuentas a las autoridades gubernamentales... y ser sujeto a la rendición de cuentas ante los ciudadanos, ya que un Parlamento que solamente se autoregula y autoevalúa, no rinde cuentas" (Puente, 2011:163).

En México se ha vivido una transición gradual en cuanto a la concepción y ejercicio del derecho de acceso a la información, partiendo de la reforma política de 1977 que no estaba enfocada en concebir este dere- 
cho como una garantía para el ciudadano en la vida democrática (Luna, 2012: 28). Posteriormente, con la reforma al artículo 6o. constitucional en 2007 y las subsecuentes, se fueron determinando las condiciones necesarias para el ejercicio del derecho de acceso a la información, entendido como el derecho de toda persona "al libre acceso a información plural y oportuna, así como a buscar, recibir y difundir información e ideas de toda índole por cualquier medio de expresión" (artículo 6o. de la Constitución federal). Asimismo, conforme a la Ley General de Transparencia y Acceso a la Información Pública, el acceso a la información es un derecho humano que comprende "solicitar, investigar, difundir, buscar y recibir información” (LGTAIP en el artículo 4o.).

El derecho de acceso a la información como garantía constitucional marca un hito en lo correspondiente a la posibilidad de allegarse de datos respecto de cómo se desarrolla la gestión del gobierno. Antecede a esta reforma la expedición de la Ley Federal de Transparencia y Acceso a la Información Pública Gubernamental en 2002, que da lugar a la creación del Instituto Federal de Acceso a la Información Pública (actualmente Instituto Nacional de Transparencia, Acceso a la Información y Protección de Datos Personales, INAI), con el objeto de "promover el ejercicio del derecho de acceso a la información; resolver sobre la negativa de las solicitudes de acceso a la información y la protección de los datos personales en poder de las dependencias y entidades" (decreto del Instituto Federal de Acceso a la Información Pública del 2002).

Por su parte, la transparencia y la rendición de cuentas se consideran elementos inherentes a un régimen que se ostenta como democrático, en el cual "los ciudadanos cuentan con dos instrumentos básicos: información sobre la acción de las instituciones públicas y decisiones de sus oficiales electos; y, capacidad para premiar o sancionar a los responsables de esas acciones" (Puente, 2011: 161).

El ejercicio de la transparencia en los parlamentos implica un compromiso social para la apertura del gobierno y la gestión del órgano legislativo basado en el uso de tecnologías de la información que incentive un flujo de datos más efectivo, en tiempo real y con mecanismos que socialmente puedan tener alguna incidencia respecto de cómo se materializa el acceso a la información enmarcado dentro de una política de transparencia.

Los marcos institucionales o legales constituyen sólo el punto de partida para hacer posible la transparencia. En relación con los parlamentos, las leyes ponen a disposición del ciudadano información relativa al proceso legislativo y a la gestión administrativa de los recursos presupuestales asignados a dicho órgano. Sobre el primero se debe conocer cuál es la agenda 
legislativa de cada diputado, la transmisión de las sesiones del pleno en vivo, así como de las sesiones de las comisiones, el acceso y transmisión por un canal oficial de la Asamblea de eventos organizados por los legisladores, tales como congresos y foros, la información sobre los proyectos de dictamen de leyes y proposiciones que serán discutidos por el pleno de la Asamblea previo a su aprobación. Por otra parte, en lo que respecta a la gestión de recursos públicos, se debe conocer desde el presupuesto estimado para sueldos y salarios como aquel destinado para el cumplimiento de las funciones sustantivas del órgano legislativo, ya que todo recurso en manos de los legisladores debe ser transparentado en cuanto al uso y destino final.

Hacer posible una política de transparencia constituye, a su vez, un

- paso importante en el impulso a la rendición de cuentas, la cual implica sujeción del poder en razón de la amenaza de sanciones (enforcement), comprendiendo tanto la obligación de que el poder sea ejercido de forma transparente (monitoring) como la necesidad de justificar y explicar actos y decisiones (justification) dentro de la noción de "responsabilidad" (answerability) (Schedler, 1999: 14).

De acuerdo con Schedler, "la rendición de cuentas política comprende algo más que la generación de información y la interacción de argumentos". Para que la rendición de cuentas sea completa se necesita que los actores no sólo informen y expliquen, sino que sus actos sean premiados o castigados (1999: 15).

La garantía del derecho de acceso a la información así como una política de transparencia y rendición de cuentas son elementos necesarios para avanzar en la construcción de gobiernos abiertos. En tal sentido, este modelo de gobierno pone énfasis en dos aspectos: primero en lo correspondiente al uso de tecnologías de la información que abren nuevos canales de comunicación entre representantes políticos y burócratas con la ciudadanía, a lo cual se denomina gobierno electrónico, y segundo, en lo que respecta a generar corresponsabilidad y colaboración social en los asuntos de interés público.

De acuerdo con Oszlak, gobierno abierto significa la posibilidad de una "nueva filosofía de gobierno, una modalidad de gestión pública más transparente, participativa y colaborativa entre Estado y sociedad civil" (Oszlak, 2013: 4). En este contexto, la transparencia, participación y la colaboración se manifiestan en una relación armoniosa entre ciudadanía y gobierno, valiéndose de tecnologías de la información para comunicar información, y aprovechar canales de comunicación que no impliquen necesariamente una participación directa en la definición de políticas públicas y su instrumentación (Oszlak, 2013: 19). 
El gobierno abierto recupera del concepto de gobernanza la noción de corresponsabilidad y horizontalidad en los procesos de decisiones públicas entre gobierno y ciudadanos para lograr mejores resultados en la gestión pública, considerando un "activo papel de la ciudadanía como corresponsable de la formulación de políticas, como coproductor de bienes y servicios públicos, y como contralor de los resultados de la acción gubernamental" (Oszlak, 2013: 5).

Los parlamentos abiertos deben ser espacios donde se garantice el acceso a la información legislativa, para que cumplan con las obligaciones legales establecidas en materia de transparencia, pero que tengan la capacidad de impulsar una transparencia proactiva, proporcionando datos útiles a la ciudadanía en relación con los aspectos donde exista cierta opacidad o no sea clara la función esencial que desempeñan a favor de la sociedad que representan.

En el apartado siguiente se discute acerca del trabajo legislativo en comisiones, en razón de que éste constituye un espacio donde prevalece la opacidad. El proceso legislativo se lleva a cabo alejado de los reflectores ciudadanos, y poco se conoce de una iniciativa de ley o de una proposición sino hasta que éstas han atravesado por un proceso que ha dado lugar a su aprobación; en caso de no ser aprobadas, los ciudadanos muy rara vez llegan a conocerlas.

\section{El trabajo Legislativo EN COMisiones}

En el Distrito Federal, la Asamblea Legislativa es "el órgano legislativo y autoridad local instituida” (LOALDF, artículo 1o.) y su labor consiste en "velar por los intereses sociales en las materias de su competencia, salvaguardar el Estado de derecho y la sana convivencia con los órganos de gobierno locales y poderes federales. Asimismo, actuará conforme al principio de transparencia y los mecanismos de rendición de cuentas" (LOALDF, artículo lo.).

La Asamblea se conforma por 66 legisladores, los cuales son electos por dos principios, mayoría relativa y representación proporcional. Este órgano se renueva en su totalidad cada tres años, y sus facultades, conforme la Ley Orgánica de la Asamblea Legislativa, se enfocan en proveer al Distrito Federal de la legislación necesaria para su buen funcionamiento en la atención de las demandas ciudadanas y en la búsqueda de una convivencia pacífica. Para el desahogo de sus asuntos se integran comisiones legislativas, las cuales son "órganos internos de organización para el mejor y más expedito desempeño de las funciones legislativas, políticas, administrativas, de fiscalización e investigación de la Asamblea" (artículo 28 del Reglamento para el Gobierno Interior de la ALDF). 
En las comisiones legislativas se realiza el trabajo parlamentario de análisis y dictamen, por lo que están facultadas para "conocer en el ámbito de su competencia, de las iniciativas, proyectos, proposiciones, excitativas, deliberaciones, avisos y en general cualquier asunto que le sea turnado por la Mesa Directiva del Pleno o de la Diputación Permanente, o la Comisión de Gobierno" (artículo 28 del Reglamento para el Gobierno Interior de la ALDF). Las comisiones se integran por hasta siete diputados (cada una), los cuales realizan la labor legislativa de análisis, discusión y dictamen de los asuntos que les sean turnados (artículo 30 de la RGIALDF).

El proceso legislativo que se lleva a cabo en las comisiones involucra - aspectos de orden formal establecidos tanto en el Reglamento para el Go-

- bierno Interior de la Asamblea Legislativa como en el Reglamento Interior de las Comisiones, los cuales establecen los procedimientos que se deben desarrollar en el ejercicio del proceso legislativo de análisis y dictamen de leyes, y proposiciones en asuntos de diversa índole. En el cuadro 1 se presenta dicho proceso.

\section{Cuadro i. Proceso legislativo de anÁlisis Y DICTAMEN EN COMISIONES}

\begin{tabular}{|c|c|}
\hline Procedimiento & Descripción \\
\hline \multirow[t]{2}{*}{$\begin{array}{l}\text { Sesión del } \\
\text { Pleno }\end{array}$} & $\begin{array}{l}\text { 1. Las iniciativas de ley y proposiciones son presentadas } \\
\text { y turnadas en sesión del Pleno por la Mesa Directiva, en } \\
\text { periodos de receso por la Comisión Permanente o en su caso } \\
\text { por la Comisión de Gobierno.* }\end{array}$ \\
\hline & $\begin{array}{l}\text { 2. La Coordinación de Servicios Parlamentarios envía los } \\
\text { turnos de las iniciativas o proposiciones a las comisiones según } \\
\text { corresponda. }\end{array}$ \\
\hline $\begin{array}{l}\text { Sesión } \\
\text { de comisión }\end{array}$ & $\begin{array}{l}\text { 1. Se convoca por oficio a los diputados integrantes para } \\
\text { realizar sesión de comisión, adjuntando copia de los asuntos a } \\
\text { tratar. Asimismo, es posible convocar en calidad de invitados } \\
\text { a servidores públicos o personas que por su profesión, } \\
\text { experiencia o conocimientos puedan aportar información útil } \\
\text { para el desarrollo del trabajo de la comisión. } \\
\text { 2. Se presenta formalmente a los diputados integrantes en } \\
\text { sesión de comisión las iniciativas que han sido recibidas para } \\
\text { análisis y dictamen. } \\
\text { 3. Conforme los acuerdos establecidos se da inicio al trabajo } \\
\text { de análisis y se levanta el acta correspondiente. }\end{array}$ \\
\hline
\end{tabular}




\begin{tabular}{|c|c|}
\hline Procedimiento & Descripción \\
\hline Análisis & $\begin{array}{l}\text { 1. Se realizan reuniones de trabajo con distintos actores para } \\
\text { análisis y discusión de los asuntos. } \\
\text { 2. El plazo establecido para emitir un dictamen será de } 30 \\
\text { días (hábiles) al término de los cuales se podrá solicitar una } \\
\text { prórroga a la Mesa Directiva del Pleno de hasta } 60 \text { días para } \\
\text { proposiciones y de } 90 \text { días para iniciativas. } \\
\text { 3. Cuando la solicitud de prórroga sea negada, el presidente } \\
\text { de la Mesa Directiva hará una excitativa para que se elabore } \\
\text { el dictamen, y al término de cinco días de contar con el } \\
\text { mismo, se enviará la iniciativa a la Comisión de Normatividad } \\
\text { Legislativa, Estudios y Prácticas Parlamentarias, para que emi- } \\
\text { ta el dictamen correspondiente. }\end{array}$ \\
\hline $\begin{array}{l}\text { Proyecto de } \\
\text { dictamen }\end{array}$ & $\begin{array}{l}\text { 1. Se envía a todos los diputados integrantes de la comisión } \\
\text { el dictamen del asunto para su conocimiento y observaciones. } \\
\text { 2. Si existen observaciones, se discuten y realizan los ajustes } \\
\text { conforme los acuerdos establecidos, a fin de contar con una } \\
\text { versión definitiva previo a la sesión de la comisión. }\end{array}$ \\
\hline $\begin{array}{l}\text { Dictamen en } \\
\text { comisión (es) }\end{array}$ & $\begin{array}{l}\text { 1. Se convoca a sesión de comisión para aprobar o desechar el } \\
\text { dictamen. } \\
\text { 2. En caso de ser aprobado se turna al Pleno de la Asamblea } \\
\text { o a la Comisión Permanente para su discusión y aprobación. } \\
\text { 2.1 Si el asunto fue desechado, concluye el proceso de } \\
\text { dictamen. }\end{array}$ \\
\hline $\begin{array}{l}\text { Dictamen Pleno } \\
\text {-Comisión } \\
\text { Permanente }^{* *}\end{array}$ & $\begin{array}{l}\text { 1. El asunto es discutido y votado en sesión del Pleno o de la } \\
\text { Comisión Permanente conforme el orden del día. } \\
\text { 2. Si el asunto es aprobado se turna al jefe de gobierno para su } \\
\text { publicación en la Gaceta Oficial del Distrito Federal. } \\
\text { 3. Las proposiciones aprobadas por el Pleno o la Comisión } \\
\text { Permanente deben enviarse a las dependencias, entidades, u } \\
\text { organismos públicos exhortados en dicha proposición, para su } \\
\text { conocimiento y atención. }\end{array}$ \\
\hline \multicolumn{2}{|c|}{$\begin{array}{l}{ }^{*} \text { En periodos de receso, la Comisión de Gobierno es quien está facultada para } \\
\text { turnar iniciativas de ley para su análisis y dictamen a las comisiones conforme la } \\
\text { materia de que se trate. } \\
{ }^{* *} \text { El Pleno de la Asamblea es quién puede emitir los dictámenes a iniciativas } \\
\text { de ley, en periodos de receso sólo es posible aprobar proposiciones. }\end{array}$} \\
\hline
\end{tabular}

FuEnTE: elaboración propia con base en el Reglamento para el Gobierno Interior y el Reglamento Interior de las Comisiones, ambos de la Asamblea Legislativa del Distrito Federal, y en la práctica legislativa desarrollada durante la VI Legislatura de 2012 a 2013. 
En relación con el proceso legislativo, cabe destacar que los ordenamientos de la Asamblea Legislativa no consideran la posibilidad de establecer algún tipo de sanción a los diputados integrantes de las comisiones que no hayan logrado desahogar todos los asuntos turnados en el trienio correspondiente, sino que en los registros de transparencia los datos obran como pendientes de dictamen. ${ }^{1}$

Por otra parte, es importante destacar que además de las prácticas formales, existen otras que se desarrollan sin reglas claras dentro del proceso legislativo, como es el cabildeo político, entendido como la actividad que llevan a cabo grupos interesados en influir respecto del proceso de decisión

- política. Debido a que los cabilderos actúan en beneficio de los intereses - de grupos, no se trata de una actividad que redunde en el interés general.

En 2011, durante la V Legislatura, se presentaron dos iniciativas, la Ley de Cabildeo y Gestión de Intereses para la Asamblea Legislativa del Distrito Federal, por un legislador de la fracción parlamentaria del Partido Acción Nacional, y la iniciativa con proyecto de decreto por el que se adiciona la sección 8 al capítulo I del título tercero del Reglamento para el Gobierno Interior de la Asamblea Legislativa del Distrito Federal. Sobre estas iniciativas se emitió un dictamen favorable para incorporar un título sexto al Reglamento para el Gobierno Interior de la Asamblea Legislativa. ${ }^{2}$

Por su parte, en la VI Legislatura se presentó la iniciativa de la Ley que regula la actividad gestoría social de cabildeo en la Asamblea Legislativa del Distrito Federal ${ }^{3}$ por legisladores de la fracción parlamentaria del Partido de la Revolución Democrática (PRD). Cabe destacar que en el análisis y discusión del tema no se contempló la participación de la Comisión de Transparencia a la Gestión, situación que es necesaria hacer notar en virtud de la transcendencia de la materia para avanzar en la construcción de un parlamento abierto. A su vez, es importante referir que dicha iniciativa no fue un asunto trascendente en la VI Legislatura, por lo que se trata de

1 Lo anterior puede verificarse en el portal de transparencia de la Asamblea Legislativa, consultando el artículo 16, fracción IV, http://www.aldf.gob.mx/video/articulo-16-800-16. html.

2 Asamblea Legislativa del Distrito Federal, "Impulsa Ley de cabildeo y gestión de intereses", http://aldf.gob.mx/comsoc-impulsa-ley-cabildeo-y-gestion-intereses--8808.html. Para consultar la segunda iniciativa, http://www.aldf.gob.mx/archivo-2c05961b88273109791e20 dl9dlf82df.pdf, y para revisar el dictamen, http://www.aldf.gob.mx/archivo-3269d9ab2e52b$9 c d 29 d c 03 e d 536 b d d 7 c . p d f$.

3 Iniciativa con proyecto de decreto por el que expide la Ley que regula la actividad gestoría social de cabildeo en la Asamblea Legislativa del Distrito Federal, http://www.aldf. gob.mx/archivo-9f06c44be4fa832798e2991409646536.pdf. 
un tema pendiente en la VII Legislatura; una deuda con la transparencia y la rendición de cuentas por parte de este órgano legislativo.

El siguiente apartado consiste en una revisión del trabajo legislativo en comisiones respecto del cual, para efectos del presente ensayo, está centrado en la Comisión de Transparencia a la Gestión por la naturaleza y relevancia de los temas que son de su competencia. Se busca conocer si derivado de su labor pueden identificarse avances y retos en términos de transparencia parlamentaria y en lo que respecta al trabajo legislativo que hayan realizado la V y VI Legislaturas a favor de un parlamento abierto.

\section{La Comisión de Transparencia a la Gestión}

Fue creada en 2009; su misión inicialmente fue la de "favorecer y promover el derecho de acceso a la información, la protección de datos personales y de archivos, así como garantizar la transparencia en la gestión de la administración pública en todas sus esferas, mediante la emisión de leyes que permitan en términos normativos colocar a la Ciudad de México a la vanguardia en esta materia" (Plan de Trabajo 2010, Comisión de Transparencia a la Gestión).

En el Plan de Trabajo de 2009 se establecieron como sus principales funciones y atribuciones aspectos relativos a (Comisión de Transparencia a la Gestión, Plan de Trabajo, 2009):

a) Favorecer y proteger el derecho de acceso a la información pública, y el correcto uso de datos personales y de archivos;

b) Emitir y/o dictaminar reformas legislativas en la materia;

c) Colaborar en los trabajos que el Instituto de Acceso a la Información Pública del Distrito Federal (Infodf) realice en materia de transparencia y rendición de cuentas;

d) Fomentar la firma de convenios con organizaciones de la sociedad civil, sindicatos y otros organismos, a efecto de difundir la cultura de transparencia;

e) Vigilar el cumplimiento de las obligaciones en materia de transparencia de los entes públicos del Distrito Federal;

f) Establecer un sistema de planificación de la gestión de las instituciones con indicadores de transparencia, desempeño y resultados, con vinculación al presupuesto, que contemple mecanismos de participación y contraloría ciudadana.

g) Adoptar un sistema de evaluación y rendición de cuentas; 
h) Realizar foros, talleres y mesas de trabajo a efecto de llevar a cabo la difusión y promoción de la cultura de la transparencia en la ciudad;

i) Citar a comparecer a servidores públicos del Distrito Federal cuando se esté discutiendo algún asunto relativo a la transparencia en la gestión gubernamental;

j) Solicitar la colaboración de la oficina de información pública de la Asamblea Legislativa;

k) Tratar lo relativo al tema de tecnologías de la información, utilizando Internet como mecanismo fundamental para el tema de transparencia en la ciudad.

- En relación con la amplitud de las funciones establecidas desde el primer plan de trabajo aprobado por dicha Comisión, se observa en el siguiente cuadro el trabajo legislativo desarrollado en las dos últimas legislaturas en el periodo 2009-2015:

Cuadro 2. Comisión de Transparencia de la Gestión 2009-20i5

\begin{tabular}{|l|l|l|}
\hline Características & V Legislatura 2009-2012 & \multicolumn{1}{|c|}{ VI Legislatura 2012-2015 } \\
\hline $\begin{array}{l}\text { Periodicidad } \\
\text { de sesiones }\end{array}$ & $\begin{array}{l}\text { Instalada en octubre de } \\
2009 . \\
\text { Sesionó dos ocasiones en } \\
\text { noviembre y diciembre de } \\
2009 . \\
\text { En } 2010 \text { sesionó en tres } \\
\text { ocasiones en enero, abril } \\
\text { y junio. } \\
\text { De } 2011 \text { y 2012 no se dis- } \\
\text { ponen datos. }\end{array}$ & $\begin{array}{l}\text { Instalada el 17 de octubre de 2012. } \\
\text { En junio de 2013 se llevó a cabo su } \\
\text { primera sesión ordinaria. } \\
\text { De octubre de } 2012 \text { a diciembre } \\
\text { En } 2014 \text { sólo se convocó a sesión } \\
\text { en febrero. } \\
\text { Del periodo enero-junio de 2015 } \\
\text { no se dispone de información en el } \\
\text { portal de internet de la Asamblea } \\
\text { sobre el registro de sesiones del } \\
\text { 2015. }\end{array}$ \\
\hline $\begin{array}{l}\text { Trabajo } \\
\text { legislativo }\end{array}$ & $\begin{array}{l}\text { De 2009 a 2010 la Comi- } \\
\text { sión presentó en sus reu- } \\
\text { niones de trabajo: }\end{array}$ & $\begin{array}{l}\text { En el periodo 2012 a 2015 le fueron } \\
\text { turnadas treinta y tres iniciativas; } \\
\text { dos de éstas en Comisiones Unidas, } \\
\text { del total seis fueron aprobadas. } \\
\text { Los principales temas respecto de } \\
\text { los cuales versaron las iniciativas } \\
\text { fueron: }\end{array}$ \\
\hline
\end{tabular}




\begin{tabular}{|c|c|c|}
\hline Características & V Legislatura 2009-2012 & VI Legislatura 2012-2015 \\
\hline $\begin{array}{l}\text { Trabajo } \\
\text { legislativo }\end{array}$ & $\begin{array}{l}\text { 1. Plan de trabajo que } \\
\text { incorporaba: comparecen- } \\
\text { cias en Comisiones Uni- } \\
\text { das con asuntos polí- } \\
\text { tico-electorales y com- } \\
\text { parecencia en Comisiones } \\
\text { Unidas con vigilancia de } \\
\text { la Contaduría Mayor de } \\
\text { Hacienda. } \\
\text { Para } 2011 \text { y } 2012 \text { no se } \\
\text { cuenta con información. }\end{array}$ & $\begin{array}{l}\text { _ Publicación de perfiles de aspi- } \\
\text { rantes a ocupar un cargo público. } \\
\text { _ Versiones públicas de declara- } \\
\text { ciones patrimoniales de servido- } \\
\text { res públicos. } \\
\text { _ Transparentar recursos públicos } \\
\text { de fracciones parlamentarias. } \\
\text { _ Acerca de establecer un proce- } \\
\text { dimiento para nombrar al pre- } \\
\text { sidente del Instituto de Acceso a } \\
\text { la Información Pública en el DF. } \\
\text { _ Equidad de género en los cargos } \\
\text { públicos del Instituto de Acceso } \\
\text { a la Información Pública. } \\
\text { _ Acerca de la UACM: transpa- } \\
\text { rentar las evaluaciones docentes, } \\
\text { licencias de profesiones y admi- } \\
\text { siones de aspirantes entre otros } \\
\text { asuntos. } \\
\text { _ Transparencia en el uso de re- } \\
\text { cursos por fideicomisos públicos. }\end{array}$ \\
\hline $\begin{array}{l}\text { Dictámenes } \\
\text { aprobados }\end{array}$ & $\begin{array}{l}\text { En } 2009 \text { se presentaron } \\
\text { para su discusión y } \\
\text { dictamen dos iniciativas } \\
\text { de reformas a la Ley de } \\
\text { Transparencia y Acceso } \\
\text { a la Información Pública } \\
\text { del Distrito Federal y } \\
\text { otra para abrogar la Ley } \\
\text { de Austeridad y Gasto } \\
\text { Eficiente; así como seis } \\
\text { proposiciones con punto } \\
\text { de acuerdo. } \\
\text { Del } 2010 \text { no se dispone } \\
\text { de información. } \\
\text { En } 2011 \text { se aprobaron los } \\
\text { siguientes dictámenes: }\end{array}$ & $\begin{array}{l}\text { De } 2012 \text { a } 2015 \text { se aprobaron seis } \\
\text { dictámenes: } \\
\text { 1. Iniciativa para reformar los artí- } \\
\text { culos 4o., } 11,47,48,51 \text { y } 54 \text { de } \\
\text { la Ley de Transparencia y Acceso } \\
\text { a la Información Pública del Dis- } \\
\text { trito Federal (LTAIP). } \\
\text { 2. Iniciativa que reforma el artículo } \\
\text { 66, fracción IV, de la LTAIP. } \\
\text { 3. Iniciativa que reforma el segundo } \\
\text { párrafo de la fracción V del } \\
\text { artículo } 38 \text { y se adicionan las } \\
\text { fracciones VI, VIII, IX y X, esta } \\
\text { última con tres párrafos en el } \\
\text { artículo 18-bis, todos de la LTAIP. }\end{array}$ \\
\hline
\end{tabular}




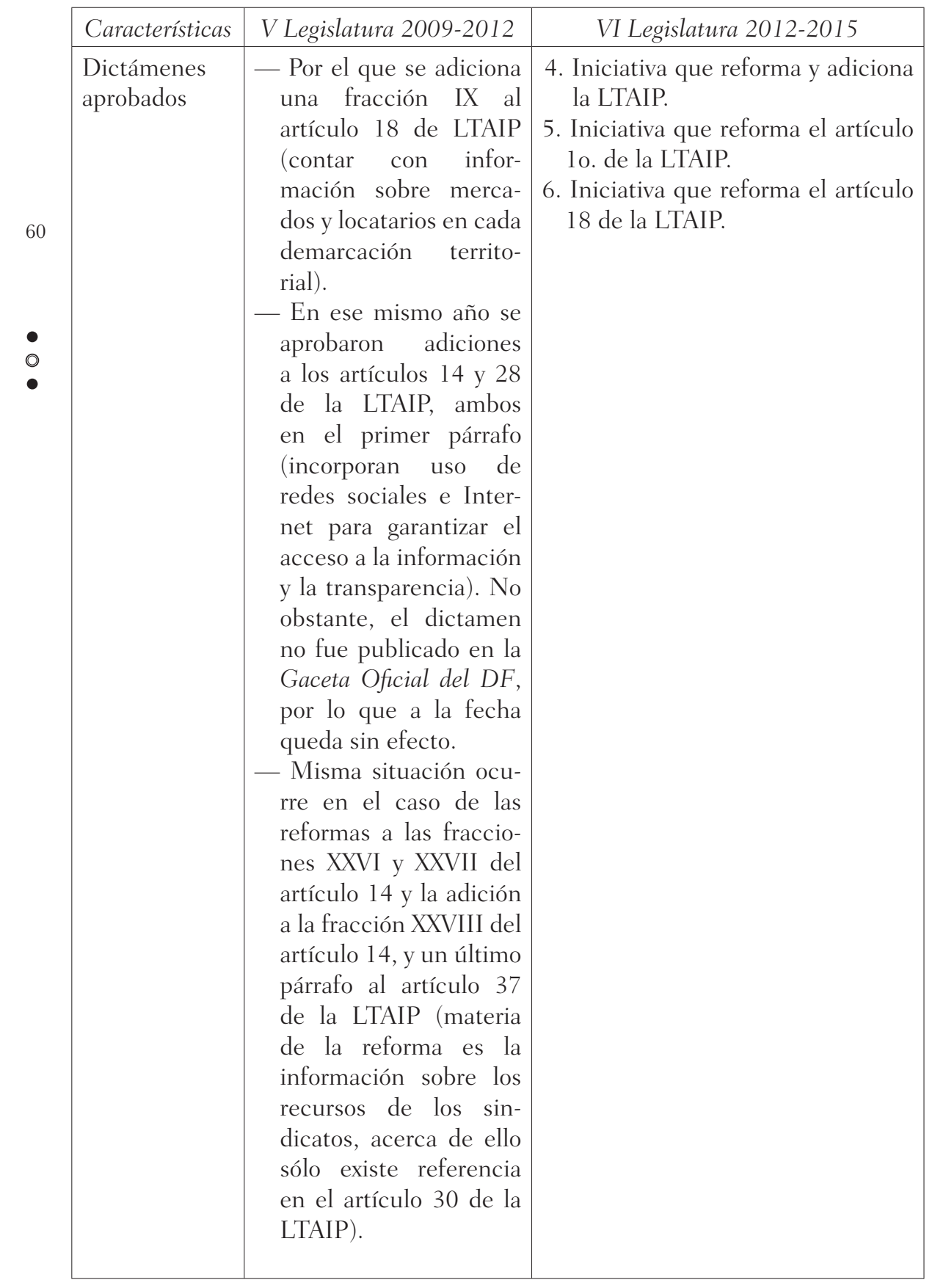




\begin{tabular}{|c|c|c|}
\hline Características & V Legislatura 2009-2012 & VI Legislatura 2012-2015 \\
\hline $\begin{array}{l}\text { Asuntos } \\
\text { pendientes }\end{array}$ & Sin datos disponibles. & $\begin{array}{l}\text { Se tiene un registro de veintiséis } \\
\text { iniciativas pendientes de la Comisión } \\
\text { de Transparencia a la Gestión y un } \\
\text { asunto en Comisiones Unidas. }\end{array}$ \\
\hline $\begin{array}{l}\text { Accesibilidad } \\
\text { de la } \\
\text { información }\end{array}$ & $\begin{array}{l}\text { La información para } \\
\text { realizar la revisión fue } \\
\text { tomada de la sección de } \\
\text { la Comisión de Transpa- } \\
\text { rencia a la Gestión V } \\
\text { Legislatura, donde se } \\
\text { consultaron listas de } \\
\text { asistencia, actas de se- } \\
\text { siones, informes y dictá- } \\
\text { menes. No obstante, se } \\
\text { observa la dificultad de } \\
\text { acceder a la información } \\
\text { considerando que no } \\
\text { se dispone de todos los } \\
\text { informes para cada año } \\
\text { de ejercicio y éstos no } \\
\text { son consistentes con los } \\
\text { dictámenes consultados, } \\
\text { lo cual impide tener } \\
\text { certeza de la producti- } \\
\text { vidad legislativa de dicha } \\
\text { Comisión en el trienio } \\
\text { 2009-2012. }\end{array}$ & $\begin{array}{l}\text { Se encuentran disponibles dos } \\
\text { versiones estenográficas de las se- } \\
\text { siones; se revisaron órdenes del día, } \\
\text { listas de asistencia y actas de reu- } \\
\text { niones de trabajo. } \\
\text { De los dictámenes que se tienen } \\
\text { en conocimiento por información } \\
\text { contenida en el orden del día y en } \\
\text { convocatorias, sólo se encuentran } \\
\text { disponibles dos en el portal de in- } \\
\text { formación sobre esta Comisión. }\end{array}$ \\
\hline
\end{tabular}

FuENTE: elaboración propia con base en documentos disponibles en el portal de transparencia en internet de la Comisión de Transparencia a la Gestión de la Asamblea Legislativa del Distrito Federal.

Conforme a los datos que se presentan respecto del trabajo legislativo de esta Comisión se establecen las siguientes consideraciones:

1. La Comisión no ha cumplido con la cantidad de sesiones por mes, que es de una sesión como mínimo.

2. La Comisión no ha dictaminado en la V y VI legislaturas, iniciativas relacionadas con impulsar un parlamento abierto, a pesar de que al menos tres iniciativas estaban relacionadas con el tema, a saber 
i) la iniciativa para transparentar recursos públicos de las fracciones parlamentarias; ii) la iniciativa de reformas a la Ley de Transparencia y Acceso a la Información Pública respecto del uso de recursos por fideicomisos públicos, y iii) la iniciativa para establecer un procedimiento para nombrar al presidente del Instituto de Acceso a la Información Pública en el DF.

3. Las prórrogas que corresponden a las iniciativas y proposiciones que le fueron turnadas en la V y VI legislaturas no se encuentran disponibles para su consulta en el portal de la Asamblea, por lo que no se puede tener certeza de que hayan dado cumplimiento a este procedimiento acorde con los plazos que determina la ley.

4. Sólo fue posible conocer el Plan de Trabajo de esta Comisión en la V Legislatura, mientras que para la VI Legislatura no se dispone de información referente a la planeación de los trabajos de esa comisión legislativa.

5. La accesibilidad de la información representa otro problema. De acuerdo con los ordenamientos legales del Distrito Federal en materia de transparencia, al inicio de cada legislatura sólo se puede tener acceso a la información de la actual y la inmediata anterior, por lo que cualquier consulta referente a las legislaturas pasadas debe ser solicitada mediante solicitud de información pública en el sistema Infomex o en la Oficina de Información Pública de la Asamblea.

A su vez, es importante tomar en consideración que la información no está actualizada, es ambigua o no está completa. Por una parte, se pueden encontrar listas de asistencia y, por otra, ausencia de actas de las sesiones, o bien, algunas versiones estenográficas de las sesiones, y no contar con todas las listas de asistencia que corroboren esa información, así como informes de un semestre, de un periodo de receso o de un año de ejercicio, sin encontrar coherencia en la forma en que presentan sus avances de gestión entre los informes.

\section{La Oficina de Información Pública}

La Oficina de Información Pública (OIP) constituye una unidad administrativa adscrita a la Dirección de Transparencia, Información Pública y Datos Personales, la cual depende dentro de la estructura orgánica de la Asamblea Legislativa de la Dirección General de Asuntos Jurídicos. 
Su función consiste en la recepción de solicitudes de información pública, así como de los datos personales en relación con el ejercicio de derechos ARCO (acceso, rectificación, cancelación y oposición). Como antecedentes de esta oficina se tiene que fue creada en 2004 como unidad dependiente de la Comisión de Gobierno, estableciéndose que tendría por objeto: "transparentar el ejercicio de la función que desempeña y garantizar el efectivo acceso a la información pública, que genera, administra y posee, misma que se considera como un bien de dominio público" (acuerdo de la Comisión de Gobierno por el que se instala la Oficina de Información Pública de la ALDF, III Legislatura, 2004).

En 2007, durante la IV Legislatura, mediante acuerdo de la Comisión de Gobierno se incorpora a la Oficina de Información Pública (OIP) en la estructura de la Dirección General de Asuntos Jurídicos de la Oficialía Mayor; al respecto destaca el papel del director general en lo referente a las respuestas que da la OIP ante la ciudadanía, quien es el encargado de dirigir las reuniones del Comité de Transparencia en representación del Oficial Mayor de la Asamblea.

En los siguientes apartados se enuncian las principales funciones y procedimientos que lleva a cabo la OIP en la atención de solicitudes de información pública y datos personales.

\section{Procedimientos de la OIP}

Los procedimientos de recepción, registro y atención de solicitudes de acceso a información pública y para el ejercicio de derechos ARCO se encuentran establecidos en el Manual de Políticas y Procedimientos de la Dirección de Transparencia e Información Pública de la Asamblea Legislativa del Distrito Federal.

Dichos procedimientos cuentan con tiempos establecidos para dar respuesta a los requerimientos ciudadanos de información, de diez días hábiles y hasta un periodo igual de prórroga para información pública, y 5 días hábiles para información pública de oficio, términos que también son aplicables para negar una solicitud por considerarla como información reservada (artículo 42 de la Ley de Transparencia y Acceso a la Información Pública). Los trámites, a su vez, cuentan con una caducidad, ya que una vez que se cuente con la respuesta, se tienen treinta días para que el ciudadano conozca de la atención a su solicitud de acceso; transcurrido ese tiempo deberá realizar una nueva solicitud. 
Para el procedimiento de ejercicio de derechos ARCO sobre datos personales en posesión de la Asamblea Legislativa, se establece un plazo de cinco días para emitir una prevención cuando existan inconsistencias en la petición; quince días hábiles para determinar si la solicitud resulta procedente, y de diez días hábiles para dar la debida respuesta. Se considera también que el solicitante debe acreditar su identidad ante la Dirección de Información Pública para el ejercicio de cualquiera de los derechos ARCO.

Asimismo, como parte de estos procedimientos, el artículo 41 de la Ley de Transparencia y Acceso a la Información Pública señala que el ente obligado debe clasificar la información antes de dar respuesta a una solici-

- tud, y que la unidad administrativa que posea o genere la información es quien está en posibilidad de proponer la clasificación ante el Comité de Transparencia a través del OIP del órgano legislativo.

Conforme a lo ya referido, se cuenta con procedimientos actualizados respecto a la atención de solicitudes de información pública, de oficio y datos personales; asimismo, el uso del sistema Infomex permite realizar las peticiones de información desde internet y recibir respuesta a través de este medio.

\section{Solicitudes de información pública}

En los últimos 10 años se ha manejado una tendencia creciente del periodo 2004 a 2014 en cuanto a la cantidad de solicitudes de información pública recibidas por la OIP; por ejemplo, de febrero a diciembre de 2004 se recibieron sólo 50 solicitudes, de las cuales 23 fueron atendidas favorablemente. Para 2005 la cifra aumentó a 94, y en 2006 a 350 solicitudes (Avilés, 2007).

Por otra parte, en una reunión de Trabajo del Comité de Transparencia del 1o. de febrero de 2013, el director general de asuntos jurídicos señaló como parte del informe estadístico de solicitudes de transparencia, que de 2012 al 30 de enero de 2013 a la Asamblea habían llegado un total de mil 962 solicitudes de información, de las cuales cerca del 50\% estaban dirigidas a las áreas administrativas del órgano legislativo, el 20\% a las áreas legislativas (comisiones, comités y trabajo de los diputados) y el restante $30 \%$ eran solicitudes no relacionadas con la Asamblea Legislativa (Comité de Transparencia, 2013).

En relación con la cifra dada por el servidor público de la Asamblea, en 2012, conforme a los registros del portal de transparencia, se encuentran 
disponibles tres informes (uno trimestral, otro semestral y otro de enero a septiembre).

El primero comprende el periodo enero-marzo y registra 500 solicitudes de información pública y 7 de datos personales. El segundo de enerojunio, con un registro de 913 solicitudes y, el tercero de enero-septiembre registró 1,219 solicitudes de información pública; de las cuales 1,141 fueron atendidas, 75 canceladas, 2 pendientes y 1 prevenida. En materia de datos personales se registraron 21 solicitudes, de las cuales 17 fueron canceladas (por no atender la prevención), 3 procedentes y una prevenida (Comité de Transparencia, 2013). Cabe señalar que conforme los datos en los informes revisados, no se logró ubicar la cifra exacta dada por el director general de asuntos jurídicos de la Asamblea Legislativa.

Los datos ya referidos son relevantes en razón de que a través de éste es posible conocer cómo han ido en aumento la cantidad de solicitudes de información y datos personales, lo cual es muestra de que cada vez más ciudadanos encuentran utilidad en hacer uso de estas herramientas de acceso a la información. En relación con los temas objeto de interés de las solicitudes, no se encontraron informes que den cuenta de esa información, la cual no permite conocer el sentido de las mismas.

\section{Transparencia en recursos públicos}

En 2007, la transparencia era más limitada en relación con la información disponible sobre el trabajo de los diputados, su planeación, y presupuesto asignado, por lo que escasamente se rendían cuentas. La cifra estimada para ese año, como recursos recibidos por cada diputado, era de 250 mil pesos mensuales (Reveles, 2013: 24). Esto implica una cifra aproximada de 3 millones de pesos anuales para desarrollar el trabajo legislativo.

En 2014, es posible encontrar bajo la leyenda "Recursos Mensuales Diputad@s”4 en el portal de transparencia en internet de la Asamblea que los legisladores reciben mensualmente una dieta neta para cada diputado de \$51,776.39; además de \$15,000 para renta del Módulo de Atención, Orientación y Quejas Ciudadana; \$7,000 para el pago de servicios del módulo y $\$ 10,183.85$ para gastos del mismo. A su vez, reciben recursos por el Programa de Apoyo a la Gestión por un monto de \$74,500.00 de forma semestral. Respecto de ese último recurso, se debe rendir un informe ante

4 Recursos mensuales a Diputad@s, http://www.aldf.gob.mx/media/avisos/programa_ de_apoyo_a_la_gestion.pdf. 
los coordinadores del grupo parlamentario, quienes a su vez integran un informe general de los diputados de su corriente política, mismo que es entregado a la Comisión de Gobierno.

Las cifras dadas son útiles ya que permiten conocer la cantidad de recursos con los que cuentan los representantes políticos de este órgano legislativo. Sin embargo, los informes entregados a Comisión de Gobierno no son públicos, y del resto de los recursos ya enunciados se desconoce, por ejemplo, la forma en que son administrados para la operación de los módulos de atención de cada diputado, pese a que existe un Manual de Procedimientos para la Asignación y Comprobación de Fondos para el Funcio- namiento y Operación de los Módulos de Atención, Orientación y Quejas

- Ciudadanas (2011). ${ }^{5}$

En dicho manual se especifican las distintas formas de comprobar los gastos de los módulos ya referidos, conforme a las necesidades de gestión de los diputados, y se establecen límites a través de porcentajes para realizar comprobaciones por concepto de gastos, como impresiones y publicaciones $(20 \%)$, comida preparada $(20 \%)$, gasolina y pasajes $(15 \%)$, telefonía celular y/o radio comunicación (20\%), copias (20\%), gastos menores no sujetos a comprobación (10\%). Esta información es procesada por la Dirección y Control de Módulos, la cual debe emitir mensualmente el informe respectivo al Comité de Administración de la Asamblea. Por último, acerca del trabajo de atención ciudadana que se realiza en los módulos, los diputados deben informar semestralmente a la Comisión de Gobierno sobre la atención a las peticiones y quejas de los ciudadanos, así como las canalizaciones correspondientes.

\section{ANÁLISIS}

El presente apartado busca exponer los avances y retos que existen dentro de la Asamblea Legislativa en materia de transparencia parlamentaria para la configuración de un parlamento abierto. Al respecto, es importante destacar que en México el antecedente más importante en relación con el impulso a un gobierno abierto fue suscrito en 2011, año en que suscribió la Alianza por el Gobierno Abierto y se comprometió a realizar acciones concretas para mejorar los servicios públicos, implementar una política de ética

5 El fundamento jurídico del manual se encuentra en el artículo 56 del Reglamento para el Gobierno Interior, en el artículo 17, fracción VII, y el artículo 18, fracción VII de la Ley Orgánica de la Asamblea Legislativa del Distrito Federal. 
pública y ataque a la corrupción, manejar los recursos públicos con mayor eficiencia y eficacia, construir comunidades más seguras e incrementar la rendición de cuentas (Hofmann, s. a.: 444).

Por otra parte, en el orden de gobierno local, el 18 de junio de 2013 la Asamblea Legislativa del Distrito Federal signó el acuerdo "Parlamento Abierto: una nueva relación con la ciudadanía” con la Organización Civil Transparencia Mexicana ${ }^{6}$; con la firma de dicho documento, este órgano legislativo se compromete a avanzar en el cumplimiento del decálogo por un parlamento abierto.

Posteriormente, en 2014, se da a conocer el "Diagnóstico sobre el Parlamento Abierto en México”, realizado por la Alianza por un Parlamento Abierto, el cual se basó en una metodología colaborativa de doce organizaciones sociales integrantes del grupo impulsor de la Alianza, quienes revisaron documentos como la Declaración sobre la Transparencia Parlamentaria y utilizaron los 10 principios del parlamento abierto, así como un conjunto de 150 variables derivadas de éstos, presentando resultados para las 31 entidades federativas y el Distrito Federal considerando una escala de 0 a 1, donde cero indica "No cumple" y uno indica "Cumple".

Para la Asamblea Legislativa del Distrito Federal el diagnóstico señaló los siguientes resultados en términos de grado de cumplimiento:

\section{Cuadro 3. Principios APA}

\begin{tabular}{|l|c|}
\hline Principios Alianza por un Parlamento Abierto (APA) & $\begin{array}{c}\text { Grado de } \\
\text { cumplimiento } \\
\text { de la ALDF (\%) }\end{array}$ \\
\hline $\begin{array}{l}\text { Derecho a la información: garantiza el derecho de acceso a } \\
\text { la información sobre la que producen, poseen y resguardan, } \\
\text { mediante mecanismos, sistemas, marcos normativos, proce- } \\
\text { dimientos, plataformas, que permitan su acceso de manera } \\
\text { simple, sencilla, oportuna, sin necesidad de justificar la } \\
\text { solicitud e imparciales. }\end{array}$ & 100 \\
\hline
\end{tabular}

6 Para revisar los discursos íntegros que señalan esta colaboración por parte de la Asamblea Legislativa y Transparencia Mexicana del diputado Manuel Granados Covarrubias, presidente de la Comisión de Gobierno en la VI Legislatura y de Federico Reyes Heroles, presidente del Consejo Rector de Transparencia Mexicana, http://www.tm.org.mx/ parlamento-abierto-firma-del-acuerdo-de-colaboracion-entre-la-aldf-y-tm/. 


\begin{tabular}{|c|c|}
\hline Principios Alianza por un Parlamento Abierto (APA) & $\begin{array}{c}\text { Grado de } \\
\text { cumplimiento } \\
\text { de la ALDF }(\%)\end{array}$ \\
\hline $\begin{array}{l}\text { Participación ciudadana y rendición de cuentas: promueven } \\
\text { la participación de las personas interesadas en la integración } \\
\text { y toma de decisiones en las actividades legislativas; utilizan } \\
\text { mecanismos y herramientas que facilitan la supervisión de } \\
\text { sus tareas por parte de la población, así como las acciones } \\
\text { de control realizadas por sus contralorías internas y los } \\
\text { demás organismos legalmente constituidos para ello. }\end{array}$ & 75 \\
\hline $\begin{array}{l}\text { Información parlamentaria: publican y difunden de manera } \\
\text { proactiva la mayor cantidad de información relevante para } \\
\text { las personas, utilizando formatos sencillos, mecanismos de } \\
\text { búsqueda simples y bases de datos en línea con actualización } \\
\text { periódica sobre análisis, deliberación, votación, agenda par- } \\
\text { lamentaria, informes de asuntos en comisiones, órganos de } \\
\text { gobierno y de las sesiones plenarias así como de los informes } \\
\text { recibidos de actores externos a la institución legislativa. }\end{array}$ & 76 \\
\hline $\begin{array}{l}\text { Información presupuestal y administrativa: publican y } \\
\text { divulgan información oportuna, detallada sobre la ges- } \\
\text { tión, administración y gasto del presupuesto asignado a } \\
\text { la institución legislativa, así como a los organismos que lo } \\
\text { integran: comisiones legislativas, personal de apoyo, grupos } \\
\text { parlamentarios y representantes populares en lo individual. }\end{array}$ & 33 \\
\hline $\begin{array}{l}\text { Información sobre legisladores y servidores públicos: requie- } \\
\text { ren, resguardan y publican información detallada sobre los } \\
\text { representantes populares y los servidores públicos que lo } \\
\text { integran, incluidas la declaración patrimonial y el registro de } \\
\text { intereses de los representantes. }\end{array}$ & 50 \\
\hline $\begin{array}{l}\text { Información histórica: presentan la información de la activi- } \\
\text { dad legislativa que conforma un archivo histórico, accesible y } \\
\text { abierto, en un lugar que se mantenga constante en el tiempo } \\
\text { con una URL permanente y con hiperenlaces de referencia } \\
\text { de los procesos legislativos. }\end{array}$ & 100 \\
\hline
\end{tabular}




\begin{tabular}{|c|c|}
\hline Principios Alianza por un Parlamento Abierto (APA) & $\begin{array}{c}\text { Grado de } \\
\text { cumplimiento } \\
\text { de la ALDF }(\%)\end{array}$ \\
\hline $\begin{array}{l}\text { Datos abiertos y no propietario: presenta la información con } \\
\text { característica de datos abiertos, interactivos e históricos, } \\
\text { utilizan software libre y código abierto, y facilitan la descarga } \\
\text { masiva (bulk) de información en formatos de datos abiertos. }\end{array}$ & No cumple* \\
\hline $\begin{array}{l}\text { Accesibilidad y difusión: aseguran que las instalaciones, } \\
\text { las sesiones y reuniones sean accesibles y abiertas al pú- } \\
\text { blico, promueven la transmisión en tiempo real de los } \\
\text { procedimientos parlamentarios por canales de comunicación } \\
\text { abiertos. }\end{array}$ & 50 \\
\hline $\begin{array}{l}\text { Conflictos de interés: regulan, ordenan y transparentan las } \\
\text { acciones de cabildeo, cuentan con mecanismos para evitar } \\
\text { conflictos de intereses y aseguran la conducta ética de los } \\
\text { representantes. }\end{array}$ & No cumple \\
\hline $\begin{array}{l}\text { Legislan a favor del gobierno abierto: aprueban leyes que } \\
\text { favorecen políticas de gobierno abierto en otros poderes y } \\
\text { órdenes de gobierno, asegurándose de que en todas las fun- } \\
\text { ciones de la vida parlamentaria se incorporen estos principios. }\end{array}$ & $33^{* *}$ \\
\hline \multicolumn{2}{|c|}{$\begin{array}{l}\text { *Para este rubro sólo Coahuila registra un reporte de } 9 \% \text { de avance y el resto de } \\
\text { las entidades federativas no cuentan con algún grado de cumplimiento. } \\
{ }^{*} \text { Para este rubro sólo el Senado de la República y el estado de Puebla cuentan } \\
\text { con reportes de avances. }\end{array}$} \\
\hline
\end{tabular}

Fuente: elaborado con base en los resultados del Diagnóstico sobre el Parlamento Abierto en México, APA 2014. Los principios fueron tomados de http://www.parlamentoabierto.mx/principios/.

Estos principios son considerados un referente importante para el presente ensayo, ya que a través de éstos es posible ubicar con la información disponible sobre la Asamblea Legislativa, en cuáles rubros se ha contribuido en cierta medida a impulsar la transparencia y el parlamento abierto, derivado de la actividad en la V y VI legislaturas de los dos órganos presentados, la Comisión de Transparencia a la Gestión y la Oficina de Información Pública. 


\section{Avances}

a) Se considera un avance importante en relación con el principio de "legislar a favor de un parlamento abierto" la creación de la Comisión de Transparencia a la Gestión en 2009, ello en razón de que el acuerdo por el que se crea le dio el carácter de comisión definitiva para análisis y dictamen de asuntos relativos a su ámbito de interés. La Comisión puede legislar en materia de transparencia y rendición de cuentas; asimismo, por el carácter transversal de los temas que son objeto de ésta, puede participar en dictámenes con otras comisiones en asuntos referentes a presupuesto, fideicomisos, auditorías, desempeño en la gestión, vivienda, salud, educación, y cualquier otro rubro, en razón de la amplitud de los temas que son objeto de la misma.

b) En lo que respecta a la creación de la OIP, en 2004, como dependiente de la Comisión de Gobierno, da la impresión de que existía una preocupación importante en controlar la información legislativa que era presentada ante los reflectores sociales, no obstante que la cantidad de solicitudes de información de ese año era apenas de 50, lo cual representa una cantidad mínima en razón del total de solicitudes recibidas en 2013 que fue de 1,962. Se considera un acierto importante el traslado de la dependencia de esta Oficina a la Dirección General de Asuntos Jurídicos, y además la existencia de una Dirección de Transparencia que cuente con una estructura orgánica que le permita disponer de recursos y personal para cumplir sus funciones.

c) La OIP cuenta con procedimientos para la atención de solicitudes de información pública y de datos personales; en términos formales, cuenta con las herramientas para desarrollar su labor diligentemente. En razón de ello se cumple el principio de "derecho a la información" en el plano de lo formal.

d) La aprobación de una "Ley para hacer de la Ciudad de México una Ciudad Abierta" representa un avance sumamente relevante para el Distrito Federal ya que con ello se establece un marco jurídico enfocado en la apertura gubernamental, en el uso de tecnologías de la información, la transparencia y la rendición de cuentas. Cabe destacar que, en el marco del trabajo legislativo realizado para aprobar este ordenamiento, era adecuado contar con un dictamen en donde el trabajo legislativo se realizara de manera conjunta con la Comisión de Transparencia a la Gestión, y no sólo como un trabajo de la Comisión de Administración Pública Local. 


\section{Retos}

a) La Comisión de Transparencia a la Gestión, en relación con el principio de "Información parlamentaria", cuenta con limitada información en ambas legislaturas respecto a su trabajo legislativo; esto considerando los datos disponibles respecto de sus sesiones, convocatorias, actas, listas de asistencia, versiones estenográficas, así como en lo que respecta a dictámenes, informes, acuerdos, foros y eventos. Sobre este último rubro se señaló con antelación que los legisladores reciben recursos de manera semestral, por lo que, en el caso de la Comisión de Transparencia a la Gestión, no se dispone de información en ese sentido.

b) De acuerdo con lo anterior, el principio de "Acceso a la Información” también se encuentra condicionado en gran medida por las limitantes ya expresadas. Ello pese al grado de avance del 100\% que es dado en el diagnóstico, ya que este porcentaje se limita al cumplimiento en un ámbito formal en cuanto a los aspectos de carácter normativo y procedimental.

c) La Comisión de Transparencia a la Gestión debe erigirse como el espacio de análisis y discusión en el cual se legisle para favorecer avances en términos de parlamento abierto. Así, durante la VI Legislatura, el jefe de gobierno del Distrito Federal envío al órgano legislativo la iniciativa con proyecto de decreto por el que se expide la Ley para hacer de la Ciudad de México una Ciudad Abierta. En el Dictamen de esta iniciativa no se incluyó la participación, ni opinión de la Comisión de Transparencia a la Gestión, sino que los trabajos se desarrollaron desde la Comisión de Administración Pública Local. Al respecto, cabe señalar la diligencia con que fue atendida dicha iniciativa, recibida en la Comisión de Gobierno el 21 de abril de 2015 y, para el 28 de abril ya se contaba con un dictamen, el cual fue presentado al Pleno y aprobado por unanimidad. ${ }^{7}$ En este sentido, el proceso legislativo de la comisión dictaminadora en razón de una iniciativa de tal magnitud debería ser conocido y difundido; sin embargo, es resultado de un proceso opaco, que no dejó ver la trascendencia de una propuesta tan importante en materia de gobierno y parlamento abierto.

d) En relación con el principio “conflicto de interés”, el Diagnóstico APA reporta un grado de avance de "no cumple". No obstante, con la aprobación de la reforma al Reglamento para el Gobierno Interior

\footnotetext{
7 Esta ley fue publicada en la Gaceta Oficial del Distrito Federal el 7 de octubre de 2015.
} 
de la Asamblea Legislativa que adiciona un título sexto, "Del cabildeo", aprobada en 2015 , se incorporan principios y establecen las condiciones generales del procedimiento de registro e intervención de las personas que en carácter de cabilderos desarrollen esa actividad en el marco de cada legislatura. Lo anterior representa un reto importante, a fin de brindar mayor transparencia al proceso legislativo a la luz del procedimiento ya referido.

e) El plan de trabajo que estableció la Comisión en la V Legislatura señala como una función y atribución: solicitar la colaboración de la Oficina de Información Pública de la Asamblea Legislativa. En este sentido, aunque el plan no es enfático en señalar respecto de qué rubros se necesita establecer dicha colaboración, lo trascedente es que se reconoce la importancia de que existan vínculos entre éstas, por lo que el reto consiste en determinar posibles aspectos de colaboración que tengan incidencia en la transparencia parlamentaria, como tales se identifican: el seguimiento puntual del cumplimiento de las obligaciones de transparencia por parte de las comisiones de la Asamblea Legislativa y de las unidades administrativas de apoyo para el cumplimiento de la función legislativa. Asimismo, la selección de criterios para clasificar y desclasificar la información como pública, de oficio y reservada, evitando la discrecionalidad con la que se realiza esta actividad actualmente.

\section{Conclusiones}

La transparencia parlamentaria representa una condición deseable en cualquier órgano legislativo. La Asamblea Legislativa del Distrito Federal en el periodo 2009 a 2015 ha atravesado por cambios importantes, de entre los cuales los más trascendentes en términos de legislación son la aprobación de una ley sobre ciudad abierta y la reforma al Reglamento para el Gobierno Interior de la Asamblea en materia de Cabildeo.

Asimismo, en relación con los órganos internos de la Asamblea, destaca la creación de la Comisión de Transparencia a la Gestión y la Oficina de Información Pública, de las cuales se ha hecho evidente que su labor puede ser más efectiva si establecen relaciones de colaboración enfocadas en fortalecer la transparencia parlamentaria.

En razón del trabajo legislativo de la Comisión de Transparencia a la Gestión en la V y VI legislaturas, no es posible observar avances relevantes en términos de legislación que haya sido aprobada por dicha comisión en 
materia de transparencia parlamentaria y rendición de cuentas. No obstante, el hecho de contar con una comisión de este tipo abre la posibilidad a que en futuras legislaturas pueda ser un espacio donde se discutan, analicen y dictaminen iniciativas en la materia.

A su vez, la Oficina de Información Pública debe dejar de ser vista como una unidad administrativa que sólo canaliza solicitudes de información y datos personales a las áreas que dentro de la Asamblea Legislativa son requeridas. Su labor puede ser mucho más útil si ésta enfocada en establecer dentro de sus procedimientos ciertos parámetros respecto a la calidad de la información con la que se responden las solicitudes de información y datos personales.

Para ello, la colaboración con la Comisión de Transparencia a la Gestión puede ser pertinente, así como también para generar criterios de clasificación y desclasificación de la información, y para establecer sanciones en razón de incumplimiento del trabajo legislativo de análisis y dictamen en comisiones al término de cada trienio. Estos aspectos pueden ser potenciales espacios de colaboración entre la Comisión y la OIP.

Por último, la transparencia parlamentaria y la rendición de cuentas constituyen retos importantes para este órgano legislativo. Como ya se ha señalado, el Diagnóstico de APA dado en 2014 ya advierte sobre los aspectos en los cuales se requiere avanzar de manera consistente; a su vez, en razón de los datos recabados y argumentos expuestos en el presente ensayo, se deja entrever que los avances y retos están centrados en aspectos de tipo normativo y en cierta medida de procesos. Sin embargo, aun con éstos, la práctica de la transparencia parlamentaria es todavía limitada en aspectos como el trabajo legislativo en comisiones y la gestión de los recursos financieros destinados a coadyuvar en el trabajo parlamentario de los diputados.

\section{BiBLIOGRAFÍA}

Avilés Chávez, María de la Luz., 2007, "Transparencia: rendición de cuentas en la ALDF”, Facultad de Estudios Superiores Aragón.

Hofmann Andrés y Ramírez Alujas, Álvaro et al. (coords.), s. a., La promesa del gobierno abierto, ITAIP-IFAI.

Luna Pla, Issa, 2012, Transparencia política, acceso a la información y consolidación democrática. El papel del TEPJF, temas selectos de derecho electoral, México, Tribunal Electoral del Poder Judicial de la Federación, núm. 28. 
Oszlak, Oscar, 2013, Gobierno abierto: hacia un nuevo paradigma de gestión pública, Red de Gobierno Electrónico de América Latina y el Caribe, Colección de documentos de trabajo sobre e-Gobierno.

Puente, Khemvirg, 2011, "La transparencia legislativa local en México", en Martí Capitanachi, Luz de Carmen (coord.), Temas selectos de transparencia y acceso a la información, Instituto Veracruzano de Acceso a la Información.

- 2009, Legislar en la oscuridad. La rendición de cuentas en la Asamblea Legislativa del Distrito Federal. Ensayos para la transparencia de la

- $\quad$ Ciudad de México, Instituto de Acceso a la Información Pública del Dis$\circ \quad$ trito Federal.

Ríos, Alejandra y Dirk, Zavala, 2012, "Las contrapartes de los órganos garantes: las unidades de acceso", en CEjudo, Guillermo et al., La política de transparencia en México, CIDE.

Schedler, Andreas, 1999, "Conceptualizing accountability", en Schedler, Andreas et al., The Self-restraining State. Power and Accountability in New Democracies, Boulder, Lynne Rienner Publishers.

Uvalle Berrones, Ricardo, 2013, Oportunidades y restricciones de la política de transparencia en México, Universidad Nacional Autónoma de México. 